\title{
O Quilombo do Ambrósio: Lenda, Documentos e Arqueologia
}

\author{
Carlos Magno Guimarães*
}

\section{Introdução}

Importante vertente da historiografia contemporânea tem se caracterizado, dentre outros aspectos, pela recuperação e valorização de fontes desprezadas pelos historiadores tradicionais. Estas têm permitido a reconstrução de aspectos da realidade mais próximos da vida cotidiana e a desmistificação da visão de mundo erigida a partir da documentação oficial, bem como um outro "olhar" sobre aqueles que aí aparecem de forma oblíqua ou mesmo figurativa. Daí a importância da investigação baseada no "entrelaçamento" de dados obtidos através de fontes diversas, cujas possibilidades abrem caminho para a apreensão de aspectos de uma realidade social que, de outro modo, permaneceriam fora do alcance de uma pesquisa que se limitasse à análise documental.

O "Projeto Quilombo do Ambrósio", inserido nesta perspectiva, tem como objetivo central a obtenção de dados que contribuam para a reconstituição histórica da dinâmica social interna daquela comunidade e de sua inserção na sociedade mineira escravista do século XVIII.

Os dados são provenientes de três tipos de fontes:

- uma lenda escrita por Cramo Gama, em fins do século XIX e publicada em 1904. Os dados nela contidos permitem reflexões diversas que vão da organização e dinâmica da sociedade quilombola à visão que 0 autor tem dos quilombos, do escravismo, dos africanos, dentre outros aspectos;

\footnotetext{
Em co-autoria com Ana F.M. Santos, Betânia D. Gonçalves e Liliana de M. Porto.
} 
- dados arqueológicos obtidos a partir de escavação sistemática na área onde se localizou o principal núcleo do quilombo, apresentando possibilidades diversas, tais como: reconstituição do regime alimentar dos quilombolas, técnicas de construção de moradias, filiações culturais a partir da decoração da cerâmica, etc.

Pretende-se, neste texto, apresentar algumas das potencialidades contidas nestes tipos de fontes.

Queremos deixar aqui nossos agradecimentos a todos que têm contribuído para o desenvolvimento do projeto, em particular à:

- Fundação Ford - Centro de Estudos Afro-Asiáticos;

- Universidade Federal de Minas Gerais:

- Museu de História Natural;

- Pró-Reitoria de Pesquisa;

- Fundação de Amparo à Pesquisa de Minas Gerais - . FAPEMIG;

- Prefeitura Municipal de Ibiá.

\section{A lenda}

A utilização das fontes referidas não se faz sem problemas. Deste ponto de vista, o estudo da lenda é o que se apresenta mais complexo e problemático, pelo seu caráter - e assim não poderia deixar de ser pouco objetivo. Isto, contudo, não diminuiu sua importância, pois, como afirma Carlo Ginzburg, "o fato de uma fonte não ser 'objetiva' [...] não significa que seja inutilizável". ${ }^{1}$ Desta forma, uma das tarefas propostas foi a identificação, ao lado de aspectos imaginários, dos elementos que possuem, parecem ou podem possuir uma base real. Esta operação, a princípio simples, pois algumas das informações contidas na lenda são claramente fictícias, torna-se complexa na medida em que o próprio autor afirma não ser a narrativa "simples produto de imaginaçåo romanesca", estando baseada em manuscrito produzido por um aluno de um ex-padre que, por sua vez, teria participado da formação do quilombo. E embora a existência deste manuscrito seja duvidosa, nota-se que Carmo Gama dispõe de informações que impressionam pela exatidão. Um exemplo é a descrição precisa que faz da localização do quilombo.

Mas a lenda pode ser analisada, também, como a expressão de uma visão de mundo que diz respeito ao autor e sua época. Neste sentido é de 
percepção imediata a tentativa de "escamotear", ou pelo menos diluir, no texto, as contradições expressas por um quilombo diante de uma sociedade escravista. Segundo o autor, o quilombo teria sido fundado por padres jesuítas durante sua fuga pelos sertões de Minas - o que é inverídico, já que a expulsão da Companhia de Jesus (1759) é posterior à destruição do quilombo (1746). Ao ligar o surgimento do quilombo à expulsão dos jesuítas, Carmo Gama introduz um elemento que, primeiro, esvazia a noção de quilombo e, segundo, acaba por retirar dos quilombolas o papel de sujeitos de uma ação que nega frontalmente o sistema escravista.

Ainda com relação a esta visão de mundo, é exemplar a descrição que faz o autor da organização interna do quilombo. Este funcionaria de forma totalmente harmônica, na completa observância de leis justas que determinavam a divisão dos habitantes em classes, "conforme as qualidades de que eram dotados" - e sob a liderança de um chefe nobre e sábio - Ambrósio - descendente de uma família real africana. As relações do grupo com a sociedade se processavam da mesma forma: era proibido aos quilombolas o exercício do saque e do roubo, bem como a incorporação de escravos que não tivessem sido comprados.

Mas, ao postular uma tal situação de harmonia, é inevitável que Carmo Gama acabe por fazer afirmações contraditórias ao longo do texto. Assim, apesar da dita proibição, e da obediência incontinenti ao chefe, "descobre-se" posteriormente que os integrantes das expedições comerciais

"não só roubavam pelo caminho, como se juntavam a outros quilombolas, para furtos, depredações, correrias e outros atos reprovados e proibidos pelas leis ambrosianas",

além de "furtarem" e "desencaminharem" escravos.

É o que reflete, também, na descrição dos membros que teriam composto inicialmente o grupo, vistos primeiro como heróis, depois como criminosos:

"nas lutas travadas (por ocasião da expulsão dos jesuítas) muitos dos escravos apenados dos jesuítas tinham embebido no sangue humano o ferro homicida de 
suas espadas, a curva de seus alfanges ou cuspido a morte pelas balas esfuziantes de seus bacamartes. Criminosos estes, não era prudente que os homens da paz os conservassem em seu rebanho [...]. Resolveram, portanto, os chefes, deixar no 'Misericordia' todos os criminosos e mais o pessoal indispensável, sob o mando absoluto de Ambrósio". 3

Há, ainda, outros aspectos a ressaltar. Carmo Gama, através da narrativa, traça um retrato idealizado da formação do "povo brasileiro", amálgama de três raças e culturas: portugueses, presentes através dos jesuítas; índios, cujas relações com o quilombo eram mais que amistosas, contando Ambrósio com elementos indígenas entre seus generais e pessoal de confiança; e, por fim, os africanos. É, aliás, pela incorporação destes últimos que o autor distancia-se - apesar da proximidade - do romantismo do final do século XIX, cujo representante maior foi, sem dúvida, José de Alencar. Tendo sido a narrativa construída apenas alguns anos após a Abolição, o elemento negro não poderia, aí, deixar de ocupar lugar de destaque.

Contudo, apesar de se notar uma recuperação da imagem do negro e do índio, vê-se também, particularmente no que tange ao primeiro, que esta é feita de forma apenas parcial: toda a herança africana é "depurada" pelo elemento português. É o que se percebe, por exemplo, através da descrição de algumas das personagens principais, a começar por Ambrósio:

"O escravo que era muito jovem, fez-se homem purificado de muitos vícios de sua nação e ilustrado o quanto possível, para o realce dos dotes que possuía ingenitos, ressaltando entre todos, o tino administrativo, a intrepidez, e mais que todos, a gratidão para com seus benfeitores". 4

O que se demonstra também na descrição de Cândida, mulher de Ambrósio, que,

"comprada pelo mesmo padre, no Vallongo, igualmente inteligente, talvez mais que Ambrósio, mostrou aptidão para a aprendizagem e da boçal africana fez se uma rapariga educada o quanto possível para sua época e 
condição, mostrando até decidido pendor para as letras, para mais uma vez provar que a bela planta não depende tanto, em certos casos, da natureza do solo, como dos cuidados do horticultor". 5

Concluindo esta parte, é possível afirmar que, apesar de problemático, o estudo deste relato tem possibilitado o levantamento de questões importantes, como a prática da religião católica entre os quilombolas e as relaçōes entre estes e as tribos indígenas da região. E, sem dúvida, apesar do caráter ficcional de grande parte das informaçōes, certamente a narrativa deverá fornecer indícios importantes, seja para o esclarecimento destas questões, seja para orientar trabalho documental - através de nomes, datas e lugares - e arqueológico - descrição das atividades agrícolas, de técnicas e instrumentos, etc.

\section{III - Os documentos}

O segundo nível no qual se desenvolve o estudo do Quilombo do Ambrósio trabalha com dados provenientes de documentos oficiais, produzidos pelas autoridades coloniais e referentes à organização e desenvolvimento da campanha repressiva contra o quilombo. ${ }^{6}$

$\mathrm{Na}$ documentação pesquisada predominam as cartas trocadas, entre si, por diversas autoridades, como o Rei e o Conselho Ultramarino; o Governador, o Ouvidor e as Câmaras da Capitania de Minas Gerais; os militares e civis participantes da tropa repressora, etc. Além desta correspondência, merecem citação os bandos - legislação de caráter circunstancial e às vezes local, criada pelo governador para a solução de problemas imediatos.

Não é o objetivo deste texto apresentar resultados conclusivos, mas a potencialidade dos documentos. A pesquisa documental, embora avançada, não se encontra concluída.

Os dados extraídos destes documentos, embora apresentem certa diversificação, dizem respeito, principalmente, às medidas tomadas pelas autoridades coloniais com o objetivo de destruir, dentre outros, o Quilombo do Ambrósio.

A primeira informação importante que os documentos permitem é a constatação do quilombo enquanto ameaça objetiva à ordem social escravista. 
Em $1^{2}$ de junho de 1746, Gomes Freire de Andrade, governador das Minas Gerais, escreveu a Antônio João de Oliveira comunicando que o havia escolhido para "Capitão, Governador e Comandante das tropas expedidas ao Campo Grande"7 devido

"à grande consternação em que os negros aquilombados no Campo Grande têm postas estas duas comarcas e o grande número que novamente concorre para os mesmos quilombos [...] e eu certo do seu grande valor, zelo no serviço de S. Magestade e do conhecimento e experiência que tem em fazer a guerra a estes bárbaros matadores adquirida nos antecedentes anos a custa de sua fazenda". 8

Mais de dois meses depois, em 8 de agosto de 1746, Gomes Freire de Andrade escrevia ao Rei de Portugal que,

"para conservar-se a Comarca, era indispensável o castigo na destruição de um tão prejudicial inimigo [...] [que] determinando-se aparecer o fazem com a indolência de queimar as vivendas, matarem os senhores delas, forçarem as famílias e levarem os escravos [...] e estando já parte da comarca não só em consternação mas precisada a despejar-se [...] [e] ia aumentando todos os dias o dano e era tanto o número de negros que diariamente se agregavam ao dito quilombo que despresada a faisca havia de atear-se um grande incêndio". 9

Um segundo tipo de informação que pode ser extraído dos documentos refere-se à organização da expedição repressiva contra os vários quilombos existentes no Campo Grande.

Em $1^{2}$ de julho de 1746, Gomes Freire de Andrade, em bando que visava regulamentar a organização da tropa que seria enviada ao Campo Grande, determinava que

"dando as Câmaras desta capitania, como fizeram para a subsistência do corpo que mando atacar os ditos quilombos, fosse esse formado de 300 a 400 homens tidos das Comarcas de São João del Rei e Vila Rica". ${ }^{10}$ 
No mês seguinte, em 8 de agosto, Gomes Freire em documento já referido anteriormente, ${ }^{11}$ prestava contas à Coroa das medidas que vinha tomando com relação ao problema, pois,

"estando já parte da comarca não só em consternação mas precisada a despejar-se, resolvi castigar esta coleção de bárbaros e com os ouvidores de Villa Rica, Sabará e São João ajustei depois de ouvidos os homens mais capazes e inteligentes, formar um corpo de 400 homens e dando-lhes munições de guerra e de boca os mandei com cabos inteligentes destruir não só este maior quilombo mas outros menores que se sabe conservarem em diferentes partes". ${ }^{12}$

As informações sobre a organização da tropa podem chegar a outros níveis de detalhamento. Na carta que Gomes Freire escreveu a Antônio João de Oliveira, em 1 de junho de 1746, informava, que havia mandado

"três oficiais de guerra às freguesias dos Carijós, Congonhas, Ouro Branco e Prados para que delas tirassem e puzessem em marcha duzentos homens armados, e ao capitão mor da Vila de São João del Rey ordenei tirasse daquela vila e suas vizinhanças sessenta homens armados que acompanhassem outros sessenta que o capitão Vicente da Costa Chaves tem incumbência de aprontar e que todos estes destacamentos estivessem o dia nove de julho no Sítio dos Cortumes adiante da ponte alta",

(onde o referido capitão Vicente da Costa deveria entregar todas as) "munições de guerra e boca" requisitadas. ${ }^{13}$

Uma das categorias sociais sempre lembrada para a composição das tropas repressoras era a dos vadios,${ }^{14} \mathrm{o}$ que se percebe na carta que o governador Gomes Freire de Andrade enviou, em 27 de junho de 1746, ao capitão-mor da Vila de São João del Rey, Manoel da Costa Gouvea,

"logo que Vmce receber esta passará aos sítios do Brumado e Santa Rita e neles e suas vizinhanças formará 
Vmce um troço de sessenta homens capazes e dos mais desocupados em que podem entrar alguns capitāes-domato[...] [e] que no dia oito do mês de julho próximo futuro se achem indefectivelmente no Sítio dos Cortumes adiante da Ponte Alta". ${ }^{15}$

O terceiro tipo de informação que pode ser obtido nos documentos diz respeito às despesas feitas com a organização, manutenção e pagamento das tropas que deveriam destruir os quilombos. $\mathrm{O}$ bando de Gomes Freire, de $1^{\circ}$ de julho de 1746 , determinava que

"a preza que se fizer de negros, negras e crias as faça conduzir com cuidado a esta vila à presença do Dr. Ouvidor Geral para se haverem de entregar os negros e negras que não forem cabeças a seus senhores pagando deles para se repartir pelo corpo que vai a esta expedição a importância de 32 oitavas por tomadia de cada um, e pelas crias que se acharem a 16 oitavas". ${ }^{16}$

Não só os senhores arcavam com as despesas da repressão. A carta de Gomes Freire a El Rei, de 8 de agosto de 1746, a qual já nos referimos anteriormente, é bastante elucidativa a respeito:

"também nos pareceu que das rendas das Câmaras se devia suprir as despesas desta expedição, mas (conhecendo o risco e o quanto se aumentava) concorreram com 2750 oitavas de ouro em que foi orçada a despesa precisa: dos armazéns mandei aprontar algumas armas, pólvora, bala e granadas e antes de sair da capitania das Minas pus em marcha a dita tropa, com o regulamento que entendi próprio para a sua conservação e bom efeito da expedição". ${ }^{17}$

Tanto as Câmaras como os armazéns reais arcavam com parte das despesas exigidas para a montagem de uma expedição contra quilombos.

Finalmente, à população cabia o restante do ônus, através da imposição de fintas, da maneira como previa a Real Ordem de 6 de março de $1741 .{ }^{18}$ Esta ordem concedia aos ouvidores o poder de 


\begin{abstract}
"repartir até trezentas oitavas de ouro por todos os moradores, sem que ninguém se escuze, as quais se repartirão só por aquela parte da comarca que se achar infestada e todos os mais que se acharem naquele circuito distância de doze léguas". ${ }^{19}$
\end{abstract}

Um quarto tipo de dados que os documentos podem fornecer diz respeito ao número de quilombolas existentes no quilombo, quantos morreram no ataque, quantos foram aprisionados, etc.

O governador das Minas Gerais, em 6 de abril de 1745, escrevia a D. Luis Mascarenhas, em São Paulo, que, naquele momento, se encontrava

"infestado o caminho de São João a Goiás com um quilombo, segundo dizem, de mais de seiscentos negros armados, estou dispondo dar-lhe o devido castigo, espero em Deus seremos bem sucedidos". ${ }^{20}$

No ano seguinte, Gomes Freire de Andrade, ao escrever para as Câmaras de Vila Rica, Mariana, São João del Rei, São José del Rei, Sabará e Vila Nova da Rainha, em 14 de junho de 1746, reafirmava o dado sobre o quilombo, onde, segundo ele,

"estão barbaramente por mais de 600 negros que consta estarem com Rei e Rainha em quilombo, a quem rendem obediência e com fortaleza, cautela e petrechos tais que se entende, pretendem defender-se e conservar-se". ${ }^{21}$

Este últivo documento citado levanta, além da provável população do quilombo, dois outros tipos de dados da maior importância:

- uma possível organização política, a nível interno do quilombo, que poderia atestar algum costume de origem africana;

- as técnicas de defesa adotadas pelos quilombolas como a construção de fortalezas ou a utilização de algum tipo de arma.

A natureza dos dados referidos permite, mesmo que de forma limitada, captar uma parte da potencialidade das informações contidas nos documentos pesquisados. 


\section{IV - A arquelogia}

A pesquisa arqueológica encontra-se em fase inicial, mas os resultados já se apresentam consistentes e promissores.

O sítio arqueológico é constituído por uma área de 1,5 hectares, delimitada em sua maior parte por um fosso em formato de ferradura, com as extremidades voltadas para o norte, terminando nas proximidades de uma mata, dentro da qual corre um filete de água.

Compondo o conjunto do sítio, destacam-se o Córrego do Ambrósio, que corre à algumas centenas de metros do fosso e desemboca posteriormente no Córrego do Quilombo e o Morro do Espia, ponto mais alto da região, num raio de vários quilômetros. A tradição oral local confirma a ligação entre os nomes destes acidentes geográficos e a existência do quilombo.

A região é montanhosa, com locais visíveis à distância e outros que só podem ser vistos quando se está muito próximo. O quilombo do Ambrósio aproveita-se destas especificidades do relevo, estando localizado na parte mais baixa de uma depressão, próximo a um curso de água perene e ao Morro do Espia.

Precedendo a escavação sistemática, foram realizadas sondagens em diferentes locais para detectar as potencialidades do sítio. Destas sondagens, as que apresentaram resultados mais expressivos foram aquelas realizadas no "interior da ferradura". Tiveram como indicadores a ocorrência de blocos de barro vermelho na superfície, evidenciando ter sido este o local ocupado pelas construções dos quilombolas.

Os vestígios obtidos a partir da escavação podem ser agrupados em vários tipos: blocos de barro, madeira carbonizada, restos de pisos de construções, fragmentos de cerâmica e restos alimentares.

Os blocos de barro são provenientes de destruição das paredes das construções que eram de pau-a-pique. Estes blocos possibilitam informações sobre as condições históricas dos homens que os produziram, constituindo, também, uma importante fonte de dados no que diz respeito à arquitetura quilombola. São de tamanho e formas diversas, apresentando cor avermelhada, que coincide com a cor do sedimento existente abaixo da superfície atual do solo, elemento básico da massa utilizada nas construções.

Estas informações são precisas e extremamente raras. Em 160 quilombos detectados na documentação pesquisada nas Minas Gerais do 
século XVII, ${ }^{22}$ não há informação sobre o tipo de construção adotada. ${ }^{23}$ Os documentos geralmente se referem às construções de "ranchos", o que não permite avançar na reconstituição deste importante aspecto da realidade quilombola.

É possível reconstituir a "malha" e a estrutura média do engradamento de madeira que sustentava as paredes das construçōes, através dos negativos de madeira encontrados em expressiva quantidade nos blocos. Estes dados são obtidos através dos diâmetros, distâncias e posições das peças de madeira no engradamento, que era formado por uma seqüência de madeiras verticais paralelas fincadas no chão, ladeadas por duas seqüências horizontais paralelas de madeiras mais finas. A fixação entre os dois tipos de madeiras se fazia com amarras de embira e/ou cipó.

Foram encontradas marcas de dedos nos blocos, constatando a não utilização de instrumentos para o manejo do barro no processo da construção.

O desenvolvimento da análise dos negativos de madeira nos blocos de barro possibilitará a identificação de espécies vegetais utilizadas na construção do engradamento, permitindo obter dados referentes ao ambiente ecológico contemporâneo do quilombo.

É importante ressaltar que a técnica de construção de pau-a-pique não exige sofisticação instrumental ou de matéria prima. Além disso, a parede exige uma cobertura leve, não sendo muito adequada para suportar telhas. Este dado pode ser confirmado no quilombo do Ambrósio, uma vez que não foram detectados vestígios de telhas, mas indícios de que esta cobertura era feita com folhas de palmeiras. ${ }^{24}$

A arquitetura de pau-a-pique com cobertura vegetal teve grande importância na sociedade escravista mineira nos séculos XVIII e XIX. Geralmente, as habitações de escravos, forros e da população miserável ${ }^{25}$ eram "ranchos cobertos de capim". ${ }^{26}$ É provável que tais ranchos fossem de pau-a-pique. A aparência das construções do quilombo não deve ter sido diferente das que ainda hoje se constróem no meio rural.

Pelo cruzamento de dados obtidos através dos negativos de madeira, marcas de dedos, aparência e textura da superfície é possível detectar que, às vezes, partes do engradamento ficavam à mostra. A exposição destas partes acontecia ou porque algumas madeiras apresentavam uma curvatura que as projetava para fora da superfície regular da 
parede, ou porque o quilombola, durante a construção, cometia algum desvio no alinhamento. De qualquer maneira, cobrir todo o engradamento não parece ter sido preocupação dos construtores.

No que se refere à espessura e textura das paredes observa-se que, em blocos onde as marcas de dedos parecem indicar suas superfícies originais, a espessura variou de 8,5 a $13,0 \mathrm{~cm}$. Já a textura apresenta-se extremamente áspera, não tendo sido detectada preocupação com alisamento ou revestimento que pudesse suavizar as irregularidades.

Outro importante vestígio é a ocorrência de um piso de barro alisado, em algumas sondagens, embaixo dos blocos desabados, permitindo inferir um padrão arquitetural que associava paredes ásperas e irregulares a um piso constituído por uma superfície de tratamento mais elaborado.

Relativamente a este, destaca-se a sua composição. A massa apresenta maior homogeneidade, não sendo encontrados pedregulhos como na massa das paredes. O processo de alisamento do piso produziu uma superfície lisa e brilhante. Apesar de não ter sido identificada a técnica deste alisamento, não se descarta a utilização de seixos rolados, ${ }^{27}$ ou mesmo de mãos e pés, que na massa podem produzir o mesmo tipo de sulcos.

A camada do piso apresenta uma espessura que vai de 2,5 a $3,5 \mathrm{~cm}$ e uma cor que varia de marrom escuro ao avermelhado. A variação da cor pode ser devida tanto à divisão espacial do trabalho quanto a uma maior incidência de cinzas e carvões que se decompuseram sobre o piso, a partir do incêndio que destruiu o quilombo.

Outro tipo de vestígio obtido são os fragmentos de madeira carbonizada (carvões) depositados sobre o piso das construçöes; preenchendo seu espaço original dentro dos blocos de barro; ou ainda, como pequenos grânulos de carvão misturados ao conjunto dos blocos em toda a área escavada. Estas formas em que os carvões se apresentam no conjunto arqueológico apontam para a confirmação da destruição do quilombo por um incêndio.

Foram encontrados, também, fragmentos de cerâmica, como cachimbos, com decoração incisa o que pode possibilitar a identificação de traços étnicos da população quilombola através da comparação com traços culturais já registrados, relativos à população escrava. A incidência de cachimbos evidentemente confirma a prática do tabagismo naquela população. 
Outros fragmentos de cerâmica foram encontrados associados a vestígios alimentares como os pedaços de uma vasilha contendo favas de diversos tamanhos. Além destas favas foram encontradas sementes ainda não identificadas e parte de uma espiga de milho. Progredir nas informações relativas à identificação das sementes possibilitará detectar hábitos alimentares dos quilombolas além de práticas agrícolas.

Resultados atingidos nesta etapa inicial da pesquisa arqueológica indicam as potencialidades do sítio, e podem ser ampliados caso surjam vestígios tais como: fragmentos de metal, vidro, porcelana, etc. Tais resultados apontam para o resgate de inúmeras possibilidades de informações, como:

- o tamanho das construções (formato, dimensões) e a divisão espacial do trabalho no interior de cada uma delas;

- a distribuição das construções no "interior da ferradura", bem como a divisão espacial do trabalho, considerando a totalidade da área;

- a identificação dos elementos da flora utilizados pelos quilombolas como alimentos, o estabelecimento dos ciclos de vida, das potencialidades alimentares, etc. Isto contribuirá para a reconstituição não só do ambiente ecológico relativo à época do quilombo, mas também do processo de interação homem-natureza;

- a reconstituição histórica da dinâmica interna do quilombo e as dimensōes da população que ali viveu.

Tudo isto vem reafirmar a importância da continuidade do projeto, que em seu gênero parece ser o único em andamento no Brasil.

\section{Notas}

1. GINZBURG, C. O Queijo e os Vermes. p.21.

2. "Quilombolas, lenda inédita mineira". p.838.

3. Idem. p.832.

4. Idem. p.834, [grifo nosso].

5. Idem. p.834, [grifos nossos].

6. Estes documentos encontram-se no Arquivo Público Mineiro e serão identificados nas notas de rodapé através da sigla SCAPM - Secção Colonial do Arquivo Público Mineiro - seguidos do numero do códice e das páginas.

7. Região onde se localizava o Quilombo do Ambrósio.

8. SCAPM. Códice 84, p.109v. a 110v., [grifos nossos].

9. Idem. Códice 45 , p.64v. e 65 .

10. Idem. Códice 50, p. 43 e v. e 44.

11. Idem. Códice 45, p.64v, e 65 .

12. Idem, ibidem. [Grifos nossos].

13. SCAPM. Códice 84, p.109v. a 110v. [Ver nota 8]. 
14. Ver SOUZA, Laura de Mello e. Desclassificados do Ouro.

15. SCAPM,. Códice 84, p.111.

16. Idem. Códice 50, p. 43 a 44, [grifos nossos]. Os preços expressos neste documento estão além dos preços normais de tomadia, já que a expedição tinha um caráter especial pela dimensăo do perigo a ser enfrentado. O Regimento dos Capitães-do-mato de 1722 que vigorou durante a maior parte do século XVIII estipulava em 20 oitavas de ouro a tomadia por quilombola recapturado.

17. Idem. Códice 45, p.64v, e 65 , [grifos nossos].

18. Idem. Códice 50, p.34v., 35 e v.

19. Idem, ibidem. [Grifos nossos].

20. SCPAM. Códice 84 , p. 75 e v., [grifo nosso].

21. Idem. Codice 84, p.108v. e 109 , [grifos nossos].

22. Uma parte destes quilombos (127) está listada em publicação que traz resultados parciais da pesquisa documental desenvolvida por este projeto. Ver GUIMARÄES, C. Magno. "Os Quilombos do Século do Ouro".

23. O único dado levantado sobre construçōes em quilombos mineiros refere-se a patamares construídos pelos ocupantes do quilombo do Guinda. Estas construçōes visavam a elevação do piso para fugir da humidade. Ver GUIMARÃES, C. Magno \& LANNA, A.L. Duarte. "Arqueologia de Quilombos em Minas Gerais".

24. É possível que outras espécies vegetais também tenham sidoutilizadas para cobertura das construções.

25. Ver, dentre outros, POHL, J.E. Viagem no Interior do Brasil; FREIREYSS, G.W. Viagem ao Interior do Brasil.

26. Ver GUIMARĀES, C. Magno. "Inconfidência, estrutura agrária e escravidão".

27. Utilizados ainda hoje para polimento de cerâmica.

\section{Bibliografia}

FREIREYSS, G.W. Viagem ao interior do Brasil. Belo Horizonte, Itatiaia, 1982.

GAMA, Carmo. "Quilombolas: lendas inédita mineira". In Revista do Arquivo Públíco Mineiro, 9(I-II), Belo Horizonte, 1904.

GINZBURG, Carlo. O Queijo e os Vermes. São Paulo, Companhia das Letras, 1988.

GUIMARÃES, C. Magno. "Inconfidência, estrutura agrária e escravidăo". In Revista do Departamento de História, 9. Belo Horizonte, FAFICH/UFMG, 1989.

-. "Os Quilombos do Século do Ouro". In Revista do Departamento de História, 6. Belo Horizonte, FAFICH/UFMG, 1988.

GUIMARĀES \& LANNA, A.L. Duarte. "Arqueologia de Quilombos em Minas Gerais". In Pesquisas, Antropologia, n 31, São Leopoldo, Instituto Anchietano đe Pesquisas, 1980.

POHL, J.E. Viagem no Interior do Brasil. Belo Horizonte, 1976.

SOUZA, Laura de Mello e. Desclassificados do Ouro. Rio de Janeiro, Graal, 1982. 